\title{
La cartografía histórica como fuente para el estudio del paisaje cultural marítimo de la Bahía de Cádiz. Una propuesta analítica y metodológica
}

\author{
Historical cartography as a source for the study of the maritime \\ cultural landscape of the Bay of Cádiz. An analytical and \\ methodological proposal \\ iD María Soledad Gómez Muñoz ${ }^{1}$
}

\begin{abstract}
Resumen
En el presente trabajo proponemos un método de estudio sustentado en la información que nos proporciona la cartografía histórica, aplicado al caso de la Bahía de Cádiz, al sur de la Península Ibérica; método basado en la corriente de estudio de los paisajes culturales marítimos formulados, por primera vez, por Chister Westerdahl. Gracias a esta metodología, hemos podido estudiar la evolución de cada uno de los factores que componen el paisaje marítimo de la Bahía; sobre todo los aspectos relacionados con el contexto físico del paisaje, además de otros elementos vinculados directamente con el desarrollo de las actividades del hombre en el ámbito marítimo, o elementos que ponen en evidencia esa idiosincrasia característica de una comunidad costera. En líneas generales podríamos decir que, este trabajo ejemplifica la utilidad de la cartografía histórica en estudios del paisaje, en donde paulatinamente va adquiriendo mayor peso como fuente de documentación primaria; sin obviar el carácter interdisciplinar e integrador tan representativos de este tipo de análisis.
\end{abstract}

Palabras clave: Paisaje cultural marítimo; Cartografía histórica; Bahía de Cádiz; análisis espacial.

Tipología: Artículo de investigación

Recibido: $29 / 06 / 2018$

Evaluado: $3 / 12 / 2018$

Aceptado: 18/03/2019

Disponible en línea: 1/05/2019

Como citar este artículo: María Soledad Gómez Muñoz. (2019). La cartografía histórica como fuente para el estudio del paisaje cultural marítimo de la Bahía de Cádiz. Una propuesta analítica y metodológica. Jangwa Pana, 18 (2), $256-$ 276. Doi: http://dx.doi.org/10.21676/16574923.2926

\footnotetext{
${ }^{1}$ Licenciada en Historia. Universidad de Cádiz. ORCID ID: 0000-0002-6170-0057. Correo electrónico: sole.gomezmunoz@alum.uca.es
} 


\begin{abstract}
In this research is proposed a method of study based on the information provided by the historical cartography in the area of the Bay of Cádiz (Spain), which is established on the study of maritime cultures from a holistic approach based on the concept of maritime cultural landscape formulated for the first time by Christer Westerdahl. This method has allowed us to study the evolution of each factor that make up the maritime landscape of the Bay, such as the physical-natural component of the landscape, as well as elements directly linked to the development of human activities in the maritime field, or elements that highlight the characteristic idiosyncrasy of a coastal community. The cartography, progressively, has been established as one of the sources of documentation of great importance for studies of such characteristics, while these conditioned, with an interdisciplinary and integrating perspective with the objective of knowing in all the points of view of the relation between man and sea.
\end{abstract}

Keywords: Maritime cultural landscape, Historical cartography, Bay of Cádiz, spatial analysis

\section{Introducción.}

Los condicionantes tan característicos que predominan en el ámbito marítimo, llegan a determinar el modo de vida de las distintas comunidades derivando, de este modo, en un vínculo singular entre el hombre y el mar. Este vínculo conlleva a la creación de comunidades con entidad propia, en donde el mar ha influido en su desarrollo e idiosincrasia constituyendo gran parte de su patrimonio cultural, el cual se materializa en aspectos cultuales, en conocimientos científicos aplicados a la navegación e incluso en la organización comercial y militar.

Como resultado, tenemos una cultura característica; para estudiarla es necesario atender a sus peculiaridades poniendo en práctica un marco metodológico concreto, aplicando técnicas específicas y optar por una postura analítica que favorezca el conocimiento de estas culturas marítimas; herramientas que encontramos en la arqueología y en la historia marítima.

\footnotetext{
${ }^{2}$ Método aplicado en el análisis cartográfico de nuestra tesis doctoral, titulada Referentes para la navegación en época romana en la Bahía de Cádiz. Un acercamiento interdisciplinar. Además, de formar parte de los trabajos de documentación desarrollados en el seno del proyecto de investigación del Plan Nacional de I+ D+ i. HAR2016-79387-P, titulado: El Contexto Arqueológico
}

Este trabajo ${ }^{2}$ constituye un ejemplo de cómo estas sociedades marítimas pueden ser estudiadas a partir de la cartografía, destacando el valor de esta disciplina, la cual, en los últimos tiempos ha ido adquiriendo un papel trascendental en estudios de índole histórica y arqueológica, como fuente de primer orden (Porro Gutiérrez, 2011, p.54; Chevallier, 2000, p.20). Es por ello, que nos hemos centrado en estudiar la información y los datos que nos proporciona la cartografía de la Bahía de Cádiz (Figura 1) desde una visión espacial; específicamente, bajo la perspectiva que comulga con la reciente teoría sobre los paisajes culturales marítimos. Para ello proponemos un modelo metodológico para el análisis de ese paisaje, abordando distintos aspectos sobre el mismo.

\section{La cartografía histórica como fuente de información}

La cartografía constituye una herramienta de apoyo para el estudio e investigación históricaarqueológica, puesto que es un complemento para el análisis y el conocimiento de los

Subacuático de la Caleta y su entorno (Cádiz): Puertos y Pecios vertebradores de una ciudad y de un territorio; en el cual participamos en el área de documentación y arqueología. 
procesos históricos desde múltiples perspectivas (Porro, 2011, p. 54). Para abordar un estudio de esta índole la cartografía histórica resulta idónea, pues nos ofrece información muy diversa, y que no solo encontramos en el propio mapa; en numerosas ocasiones la información escrita, que se encuentra anexa a estos mapas, resulta también una fuente de información muy valiosa, sobre todo para comprender e interpretar mejor el mapa.

Como veremos, la utilidad de la cartografía histórica reside en la variedad de datos que ofrece, sobre todo en lo relacionado con el espacio; estos documentos nos informan sobre la evolución geomorfológica de la costa y la naturaleza de la misma, además de la transformación de los cursos fluviales. Reflejan también el relieve costero de un período concreto, así como el posible registro arqueológico que se encuentra camuflado en el paisaje o la propia toponimia. Asimismo, para el tipo de análisis que nos disponemos a realizar, la cartografía náutica resulta extremadamente útil; una parte importante del mismo, se centra en la aproximación al paisaje en un período concreto, lo que permitirá, también, analizar diversos aspectos sobre navegación, ya que son analizables diversas variables como la batimetría, líneas de costa, relieve marino y composición de los fondos. La combinación de estos datos nos permitirá establecer análisis comparativos ${ }^{3}$.

Los mapas antiguos también ofrecen información relacionada con las actividades desarrolladas en dicho espacio, o funciones que desempeñaban determinados elementos con fines marítimos. Hablamos de puertos, elementos de señalización como los faros, o torres vigías, astilleros, explotación de salinas; así como estructuras o espacios destinados a

\footnotetext{
3 Para un correcto tratamiento de dichos datos y su posterior análisis espacial, es necesario integrarlos en los sistemas de información geográfica. Este tipo de softwares resultan una herramienta indispensable para la ejecución de análisis espaciales generando resultados mucho más que aceptables.

${ }^{4}$ La distribución y transformación de estos elementos en el paisaje marítimo son síntomas de cómo el hombre se ha apropiado del paisaje
}

actividades haliéuticas o a la manipulación y transformación del pescado ${ }^{4}$.

Por otro lado, es importante considerar también la toponimia, ya que en ocasiones testimonia la relación del hombre con el mar, su percepción y apropiación. Su estudio puede informarnos sobre la realidad morfológica de determinados espacios o los usos culturales de diferentes áreas, al vincular determinadas actividades en zonas que presentan unas características geográficas específicas o promueven alguna virtud que las hace propicias para ello (Duncan y Gibbs, 2015: $31)$.

El mayor o menor grado de implicación de esta fuente, en un estudio sobre el paisaje, dependerá, en nuestra opinión, del contexto histórico en el que se enmarque nuestro proyecto. Para estudios asociados a un contexto moderno-contemporáneo, la cartografía histórica es fundamental puesto que, la información que expresa, refleja la realidad del momento cronológico que estudiamos; la mayoría de la producción cartográfica, que suele conservarse, data de ese período. Sin embargo, para trabajos centrados en paisajes antiguos, este tipo de fuente entraña cierto valor, pero con menos trascendencia que para el caso anterior. La problemática radica en la dificultad, o casi imposibilidad, de disponer de documentación cartográfica de rigor de época prehistórica o antigua. Es por ello que el investigador debe ser consciente de la realidad transmitida por estos, y tomar la información como mera referencia o aproximación para el conocimiento de la realidad paisajística en la antigüedad; pudiendo así, extrapolar determinados elementos ${ }^{5}$ que le permitirán establecer un estudio regresivo del paisaje en cuestión. 
Lógicamente, para llevar a cabo una lectura coherente y completa, estos datos deben ser confrontados con los que ofrecen otro tipo de fuentes; de ahí el carácter interdisciplinar del estudio de paisajes culturales marítimos.

\section{Propuesta metodológica y analítica}

Todo estudio cartográfico debe partir de un corpus documental, fruto de recopilación de documentos y gestión de la documentación, recurriendo, para ello, a distintos repositorios digitales de archivos nacionales $\mathrm{e}$ internacionales, civiles y militares. Para nuestro caso, recomendamos al lector, para el inicio en esta primera tarea basada en el acopio de material, el uso del buscador creado por el Ministerio de Educación, Cultura y Deporte llamado PARES (Portal de Archivos Españoles $)^{6}$, o el portal de la Biblioteca Virtual creado por el Ministerio de Defensa ${ }^{7}$; ambas herramientas, de acceso público, ponen a nuestra disposición material de alta calidad.

La propuesta metodológica ${ }^{8}$ que aquí presentamos se centra, básicamente, en el tratamiento de la información cartográfica apoyado en un discurso analítico e interpretativo del paisaje que proponía la corriente centrada en el estudio de los paisajes culturales marítimos; es decir, estudiamos los distintos elementos que lo componen, los cuales nos ayudarán a comprender, en distintos aspectos, a esas comunidades marítimas, cuyas vidas giran en torno al mar. Amén a este discurso, podemos agrupar la información cartográfica con base en los dos enfoques en los cuales, según Westerdahl $(1992)^{9}$, debe estudiarse un paisaje cultural marítimo: analizar el paisaje cultural desde una perspectiva física- material y cognitiva, componentes insertos en el espacio natural, el

\footnotetext{
${ }^{6} \mathrm{http}: / /$ pares.mcu.es/

${ }^{7}$ http://bibliotecavirtualdefensa.es/BVMDefensa/i18n/e staticos/contenido.cmd?pagina=estaticos/presentacion

${ }^{8} \mathrm{Si}$ bien es cierto que el lector debe tener en cuenta que dicho método surgió en el marco de un estudio del paisaje romano, fundamentado en una fuente documental moderno-contemporánea.

${ }^{9}$ Propulsor, en 1980, del estudio de los paisajes bajo una perspectiva holística que se materializa bajo el concepto de paisajes culturales marítimos, en clave arqueológica
}

cual adquiere en este estudio un peso significativo.

Para facilitar una correcta lectura de todos los elementos, diseñamos un método de estudio basado en el desglose de la información cartográfica en seis bloques temáticos; en donde, a su vez, se analizan distintos componentes del paisaje cultural marítimo. Dichos bloques son: Aspectos geomorfológicos y fisonomía costera, Relieve marino y costero, Mecanismos para la movilidad, Funcionalidad del espacio marítimo, Elementos del paisaje cognitivo, Registro arqueológico ${ }^{10}$.

$\mathrm{Si}$ bien recomendamos que previamente a realizar el diagnóstico global de estos elementos contenidos en los mapas antiguos, el investigador necesita conocer las características generales de la propia producción cartográfica de la época, como el contexto histórico y la finalidad por la que fue concebida; estos datos ayudarán a la interpretación y contextualización de los diferentes componentes

La practicidad de este método queda manifiesta en los resultados obtenidos, pues, además de constituir un práctico sistema para organizar la información, si trabajamos con un gran volumen de datos, también permite llevar a cabo un estudio minucioso de cada elemento; establecer una correspondencia diacrónica y conexión entre ellos; además de permitir una mejor planificación de estudios arqueológicos y geoarqueológicos.

\section{El caso de la Bahía de Cádiz}

La naturaleza marítima y la opulencia de los recursos de la que fue característica la Bahía de Cádiz, junto a su valor geoestratégico, le ha

\footnotetext{
${ }^{10}$ La extensión del análisis para cada uno de estos elementos, como veremos, no será el mismo, ya que dependerá de la zona a la cual sometamos el estudio. Para el caso de la Bahía de Cádiz, claramente podemos observar una clara desproporción entre los diferentes bloques dado que determinados componentes son más perceptibles, en la cartografía, que otros.
} 
otorgado, desde tiempos remotos, la trascendencia por la cual numerosas culturas se han sentido atraídas. La tradición marítima de la Bahía, a lo largo de la historia, resulta más que palpable; a juzgar por la cantidad de noticias recogidas en las fuentes literarias, por los restos materiales conservados de amplia cronología y por el volumen de producción cartográfica del que ha sido objeto. De este modo, por su relevancia en la historia, por su riqueza patrimonial y sus características naturales, consideramos necesario un estudio, desde una perspectiva espacial y evolutiva, del comportamiento de las culturas marítimas y su relación con la misma.

Una parte de este estudio lo vamos a abordar con base en la documentación cartográfica producida sobre la Bahía de Cádiz, aplicando el método analítico previamente descrito.

Para acometer este análisis hemos elaborado, en primer lugar, nuestro propio corpus documental, el cual cuenta con un total de $255^{11}$ mapas procedentes de diversos repositorios digitales (Figura 1).

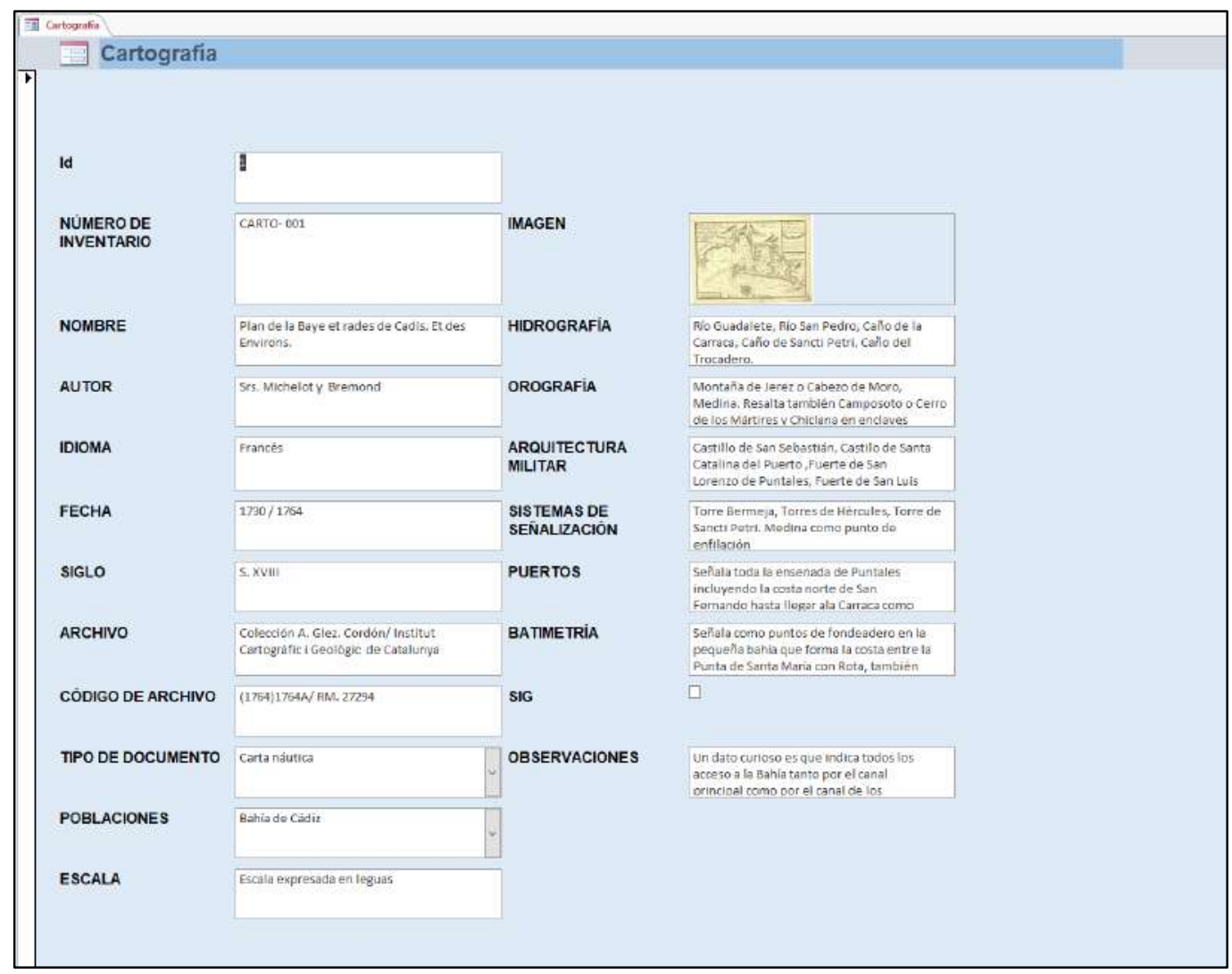

Figura 1: Imagen extraída del modelo de formulario creado para nuestra base de datos cartográfica.

Los mapas que componen este sucinto repertorio fueron seleccionados bajo un único criterio, pues se incorporaron todos aquellos en los que apareciera nuestra área de estudio general o un determinado sector, y que nos aportarán información sobre los aspectos a estudiar, independientemente de su

\footnotetext{
11 Cantidad que, a nuestro juicio, resulta meramente representativa a juzgar por el número de mapas y planos sobre la Bahía que se localizan en otros archivos nacionales e internacionales

12 Disponemos de ejemplares españoles, además franceses, ingleses y holandeses.
}

procedencia $^{12}$ o cronología. En relación a este segundo factor, es importante puntualizar que nuestra colección abarca desde la segunda mitad del s. XVI hasta finales del s. XX; fechándose el mayor volumen documental entre los siglos $\mathrm{XVIII}^{13}$ y XIX. Dicho fenómeno puede responder la propia coyuntura

\footnotetext{
${ }^{13}$ En esta fecha la cartografía experimenta cierto avance técnico influido por las innovaciones científicas, de tal modo que la producción adquiere mayor rigor en los datos que aporta (Cortés, 1998, p.47); de este modo los datos que se integran y se interrelacionan con los SIG
} 
política y económica de la época; recordemos el traslado de la Casa de Contratación a Cádiz en 1717, junto con el consecuente crecimiento y engrandecimiento que experimenta la ciudad (Bustos, 2008: 422), al que se une el conflicto bélico que tiene lugar a comienzos del s. XIX contra las huestes francesas.

Todo este corpus ha sido previamente ordenado y analizado con base en su contexto histórico, como citamos anteriormente, para una mejor comprensión de los cambios acaecidos y llevar a cabo un buen diagnóstico, estructurado a partir de la propuesta metodológica que anteriormente describimos.

\section{a) Aspectos geomorfológicos fisionómicos de la costa}

La principal característica sobre la Bahía, que nos revela la cartografía desde el s. XVI, es de una amplia rada que ofrece refugio a las naves. En estas representaciones no se aprecian las diferentes partes en las que hoy en día la Bahía se estructura, pues tanto Matagorda junto con la Isla del Trocadero y Puntales, conforman un estrecho; no se reconoce en la cartografía de la época, puesto que aparecen como una suerte de islotes próximos a la costa de Puerto Real (Figura 3). Esta situación cambia para el s. XVII, pues ahora se proyecta hacia el oeste conformando una punta de tierra que actúa como división entre la bahía exterior y el saco interior.

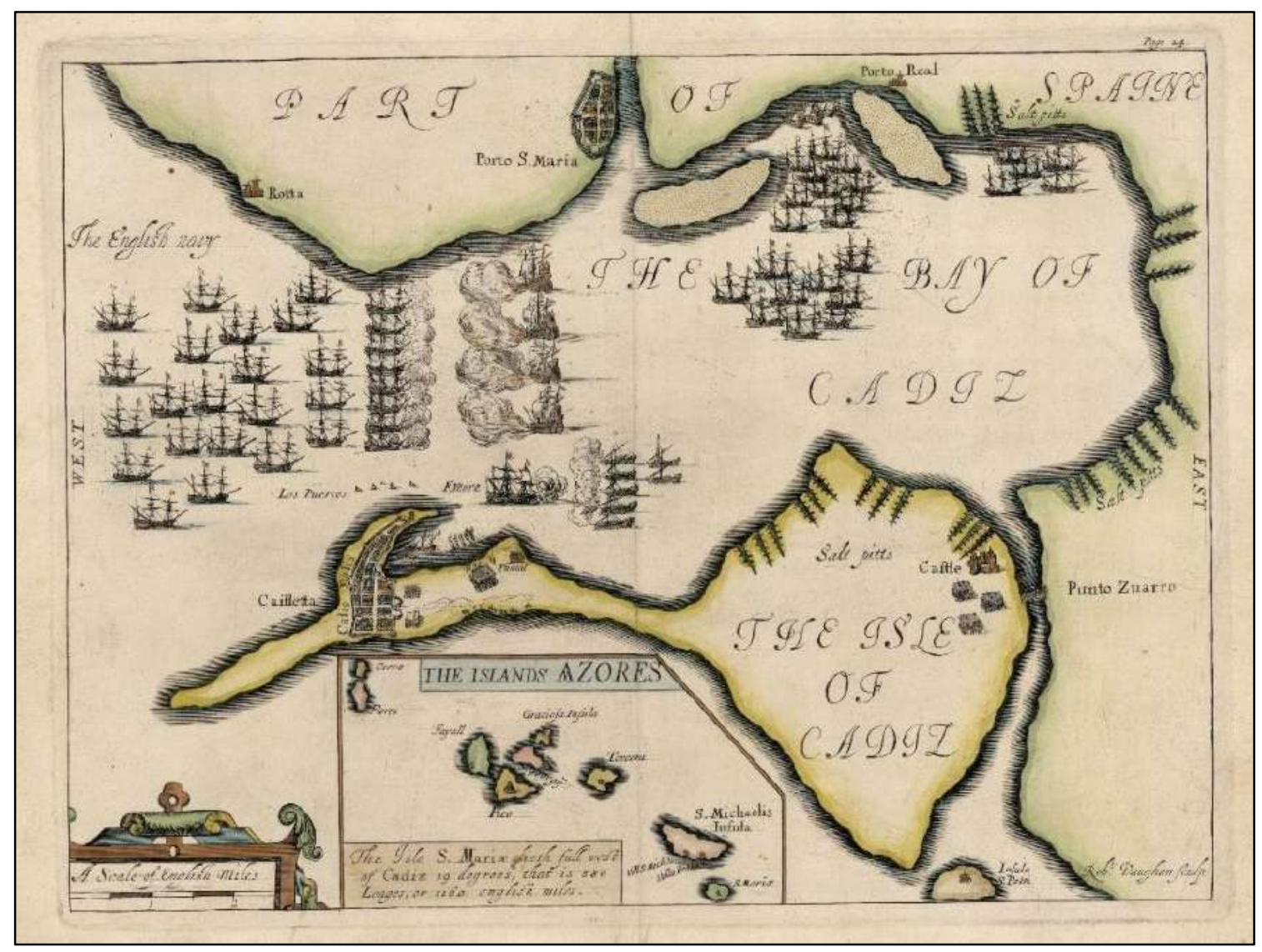

Figura 2: Ejemplo de representación de la Bahía del s. XVI (Institut Cartogràfic i Geològic de Catalunya. RM. 24655) 
En estas primeras representaciones modernas de la Bahía destaca la presencia de una gran isla denominada, tanto en la literatura como en la cartografía, como Isla de Cádiz ${ }^{14}$; su contorno tiende a presentar zonas sobredimensionadas, con cierta tendencia a la deformación y desproporción (Figura 2), como por ejemplo el engrosamiento intencionado de la zona de San Fernando; la acusada curvatura de la ensenada de Puntales o alargamiento excesivo de las puntas de San Sebastián, de San Felipe, de Santa Catalina o Puntales. Este fenómeno puede responder a la clara intencionalidad por parte del cartógrafo de indicar, por medio de este sistema, las zonas peligrosas, zonas aptas para el refugio, o destacar algún hito dadas sus características físicas; sin olvidarnos también de los rudimentarios métodos utilizados para la confección cartográfica. No obstante, esta forma de representar determinados accidentes costeros constituye un testimonio directo de la percepción del paisaje de la Bahía, enfatizando de esta forma determinadas zonas de clara utilidad náutica.

A partir del s. XVIII la situación, en cuanto a la representación del paisaje se refiere, cambia completamente. Estas mantienen cierta proporción en la representación de la Bahía, guardando relación con la escala, de modo que los contornos adquieren un cariz más realista, sin llegar a recurrir a la sobredimensión de los accidentes costeros para indicar su relevancia para la navegación.

Entre finales del s. XIX hasta mediados del s. XX (Figura 5), supuso el período en el que la Bahía experimenta la mayor transformación que ha sufrido en los últimos años; propiciada por la política de rellenos que se lleva a cabo para estas fechas, pues este proceso de aterramiento se atisba desde 1860, aproximadamente, fecha en la que se instaura el ferrocarril.

Si analizamos detenidamente los distintos espacios que componen la Bahía, podemos advertir una serie de modificaciones que han ido transformando y configurando el paisaje actual.

Un ejemplo de ello lo tenemos en la punta de tierra donde se asentó, desde el s. XVI, el citado Castillo de San Lorenzo del Puntal. Hasta el s. XVIII, y bien entrado el s. XIX, esta punta presentaba en el flanco meridional una suerte de pequeños arroyos o riachuelos que desembocaban en la misma ensenada de Puntales, conformando una pequeña caletilla. Con el transcurso de los años la cartografía, paulatinamente, fue representando este sector como un área cada vez más colmatada, en donde se podía apreciar, en ocasiones, pequeñas láminas de aguas interiores; de este modo, se evidenciaba una zona de cotas bajas y de carácter inundable. Sin embargo, a partir de la segunda mitad del s. XX, dicha zona experimentó un cambio radical al ser colmatado y rellenado; se edificó lo que hoy se conoce como el Barrio de la Laguna ${ }^{15} \mathrm{y}$, más hacia el sur, el polígono industrial de la Zona Franca, entre otras zonas. También sufre la misma suerte la franja litoral al norte de Puntales, dado que, en dicha zona, también se aplica la misma política de rellenos masivos en donde hoy se localiza el barrio de extramuros llamado Barriada de la Paz y antiguas extensiones de Astilleros, todo erigido en espacios ganados al mar (Figura 3).

\footnotetext{
14 Topónimo que aparece desde las fuentes árabes (Abellán, 2005), utilizado para denominar Cádiz y San Fernando.
} 


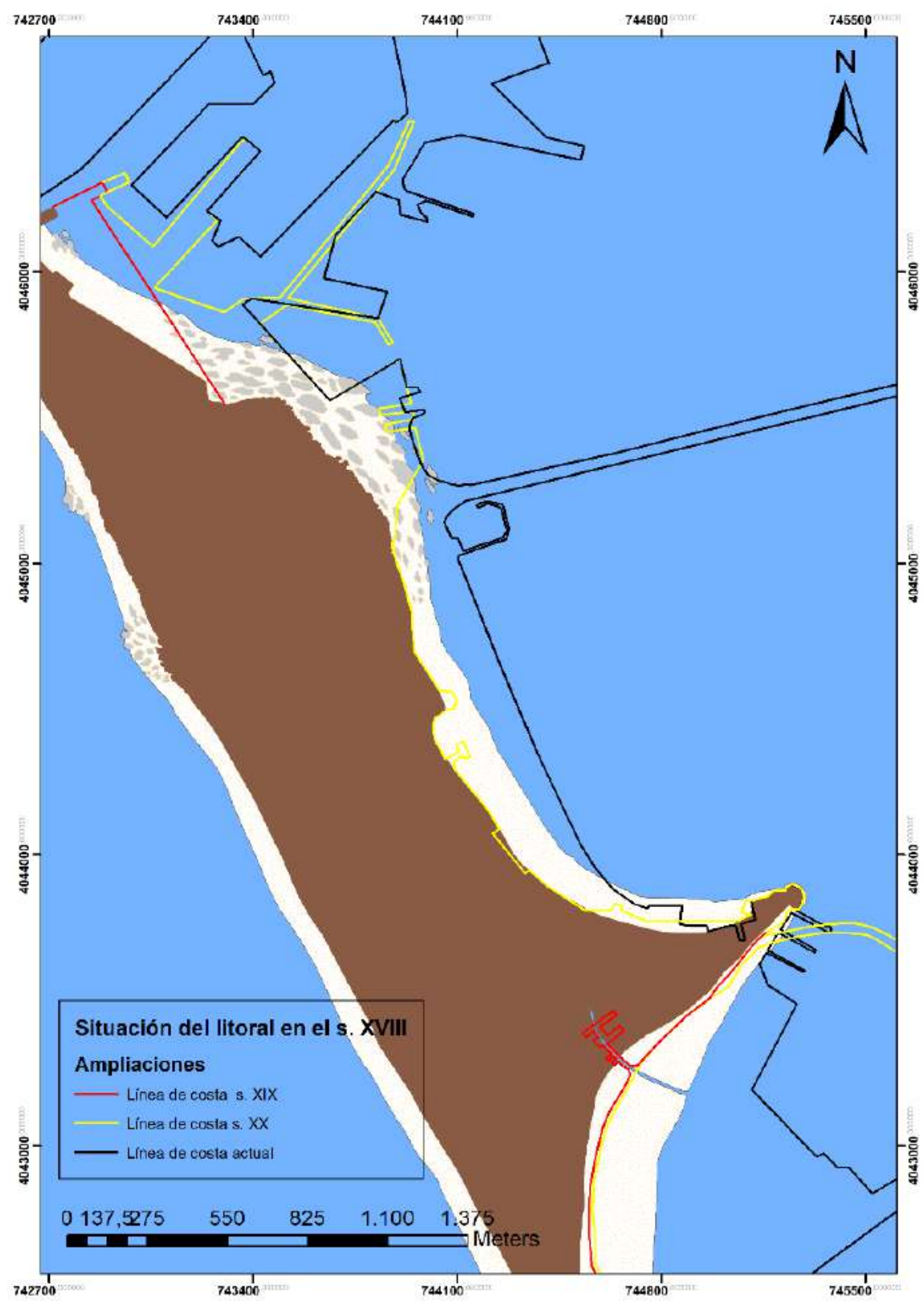

Figura 3: Representación de la costa de Cádiz durante el s. XVIII (Museo Nacional. MN, E-52-40) en la cual se superponen las diferentes líneas de costa documentadas en los s. XIX (Instituto Geográfico Nacional. S1-35-N-34), s.

XX (Real Observatorio de la Armada. ROA- 2930) y en la actualidad (Centro Nacional de Información

Geográfica.PNOA_MA_OF_ETRS89_HU29_h50_1061). Mapa elaborado con ArcMap versión 10.5

Otra zona también afectada por alteraciones artificiales es el área de Matagorda, junto con la isla del Trocadero. Estas experimentan alteraciones en cuanto a su morfología, sobretodo en el momento en el que se produce el intenso proceso de fortificación, construyendo fuertes y cortaduras a finales del s. XVIII y comienzos del s. XIX. Especialmente en Matagorda, para comienzos del s. XX, se observan cambios en cuanto a su extensión, ya que también se llevan a cabo rellenos en dirección al Bajo de la Cabezuela y se construyen muelles, además de infraestructuras para Astilleros.

A tenor de lo expuesto, el Islote de Sancti Petri constituye también otra zona que experimenta cambios, a juzgar por el modo en que es representada. En las primeras representaciones que disponemos, la situación del islote se asemeja a la de un simple promontorio aislado controlando la entrada al caño homónimo. No obstante, a partir del s. XVIII, el islote aparece también representado como una parte emergida del arrecife que se dispone 
paralelamente a la costa; incluso a veces se observa una especie de conexión con la Punta del Boquerón, pudiéndose advertir la naturaleza paleomorfológica del islote y de su posible conexión con tierra firme en un momento determinado ${ }^{16}$.

\section{También contamos con documentos} focalizados en la representación de la ciudad de Cádiz. La capital gaditana, desde el s. XVII, se muestra normalmente con cierta fidelidad en cuanto al contorno y perfil de su costa, especialmente en la zona del puerto. Cádiz aparece asentada sobre una plataforma rocosa con retazos arenosos -la playa de la Caleta y la playa que conformaba el puerto natural- hasta casi llegados al s. XIX (Figura 5); estos retazos arenosos son el testigo directo que evidencian la configuración de la ciudad en época antigua. Desde un punto de vista topográfico, y a la luz de los últimos estudios geoarqueológicos,
Cádiz estuvo dividida por un canal, en sentido este-oeste, que atravesaba la ciudad aproximadamente desde el puerto hasta la actual playa de la Caleta; hablamos del célebre canal llamado Canal Bahía-Caleta, o también Canal de Ponce (Ponce, 1985). Por tanto, la presencia de arenas en la cartografía histórica en dichas zonas, que contrastan con la costa rocosa que caracteriza el resto del perímetro, evidencia la presencia de ese antiguo canal y su naturaleza sedimentaria; fruto de la colmatación por los aportes sedimentarios fluviales ${ }^{17}$, entre otros factores. Una de las mayores transformaciones que se aprecian en la ciudad se localiza en el puerto y en la extensión de sus infraestructuras, así como la construcción perimetral de sus murallas que modifican considerablemente los acantilados naturales que se localizan en determinadas áreas.

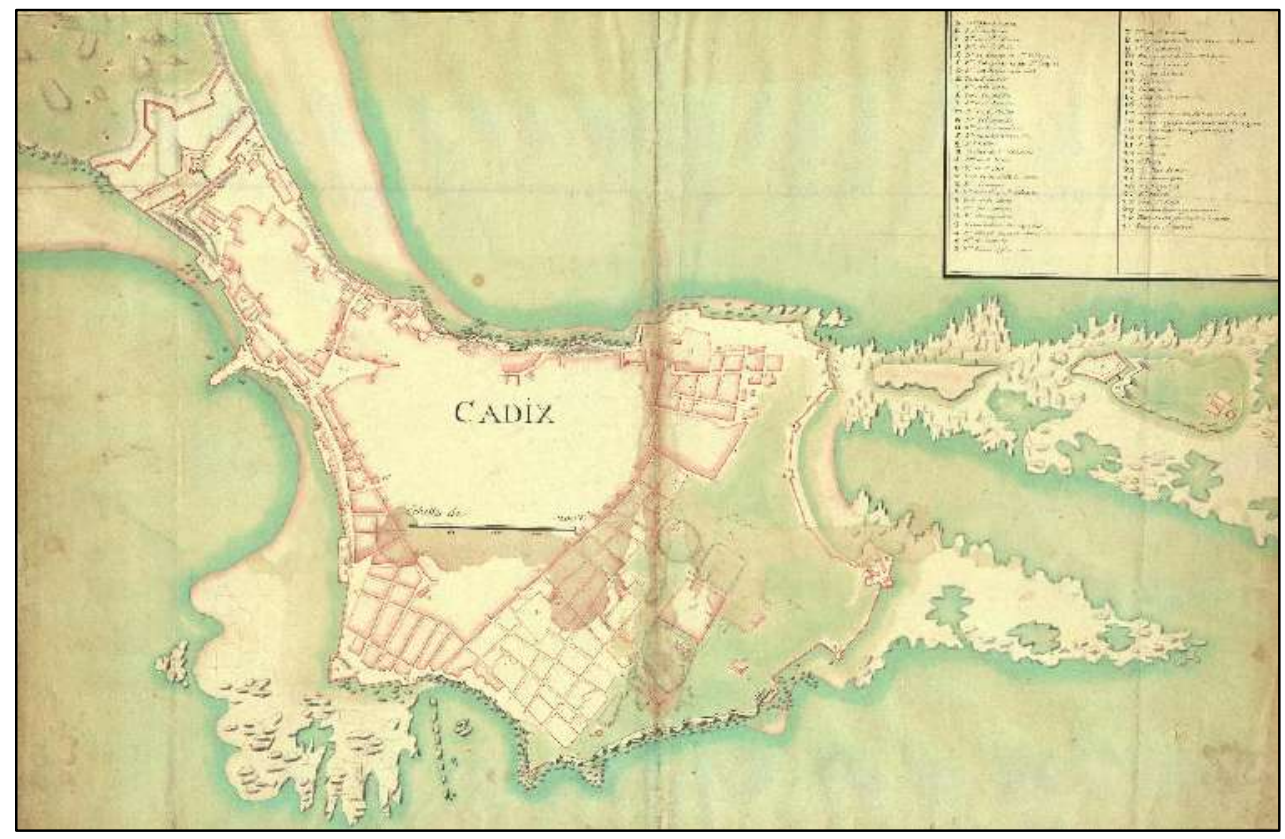

Figura 4: Plano francés de la Plaza de Cádiz, fechado en el s. XVIII. (Institut Cartogràfic i Geològic de Catalunya. RM. 24670)

Además de la evolución geomorfológica del litoral, otro factor relevante, y que domina el

\footnotetext{
${ }^{16}$ Existen numerosas hipótesis en cuanto a la recreación paleomorfológica del islote, puesto que algunos investigadores sostienen la posible unión del islote con tierra firme por la zona de Torre Bermeja (Alonso, et al. 2009, p. 18), mientras que otros manifiestan ese carácter insular en donde hipotéticamente se asentó el famoso templo de Hércules (Arteaga, et al.2008, p. 74). Un trabajo en el cual llevan a cabo toda una revisión general
}

paisaje marítimo de la Bahía y a la vez causante, en cierto modo, de importantes

de las diversas propuestas de reconstrucción paleotopográficas de esta zona la encontramos en el trabajo de Sáez Romero y Díaz Rodríguez (2012).

${ }^{17}$ Gracias a los trabajos geoarqueológicos desarrollados por el profesor Arteaga y su equipo en la capital, han arrojado luz sobre la evolución geomorfológica de casco histórico de Cádiz (Arteaga et al., 2002). 
alteraciones, son los cursos fluviales. La hidrografía es uno de los elementos en los que más se perciben modificaciones, especialmente en su estuario; cambios propiciados por agentes naturales, pero sobre todo alteraciones antrópicas ${ }^{18}$. Desde el s. XVI, el río Guadalete y el caño de Sancti Petri han sido las vías fluviales que constantemente han estado representadas en el sistema hidrográfico de la Bahía, como los cursos principales en torno a los cuales se ha articulado la navegación; el caño como vía de acceso y el río como vía de comunicación con los pueblos del interior.

En la cartografía más antigua, el Guadalete aparece como un cauce aislado y poco sinuoso que desemboca a los pies del Puerto de Santa María $^{19}$. No obstante, a partir del s. XVII, junto al Guadalete se representa el río San Pedro también llamado río Salado- el cual desemboca también en la bahía exterior al sur Guadalete; estando sendos estuarios separados por la flecha litoral de Valdelagrana, la cual experimenta también un gran cambio. En un primer momento, ambos cursos parecen constituir ríos independientes; sin embargo, en documentos más recientes, se aprecia cierta relación entre ellos, ya que en ciertas ocasiones los cursos parecen unirse en un punto en concreto y formar parte de un mismo cauce.

Por otro lado, llama especialmente la atención la extensión de terreno que existe entre estos dos estuarios hasta su aparente unión en un solo curso. En los mapas y planos del s. XVII y XVIII se percibe como una zona lagunar, $y$ pantanosa, en donde predominan explotaciones salineras adosadas a la margen izquierda del Guadalete. De este modo, la imagen que se desprende de este paisaje, a través de la cartografía, es de una zona que aparentemente todavía se encuentra en proceso de colmatación, ya que en determinados casos aún se perciben ramales del río San Pedro que se adentran en estas tierras y láminas de agua,

\footnotetext{
${ }_{18}$ Nos referimos, por ejemplo, al número de obras de desviación llevadas a cabo en los cauces del Guadalete y del río San Pedro.

${ }^{19}$ Desembocadura que según sostiene López Amador y Pérez Fernández (2013) fue una obra de ingeniería
}

las cuales, en documentos más modernos no se aprecian. Este paisaje casa perfectamente con las numerosas teorías sustentadas en estudios geológicos y geoarqueológicos aplicados en el entorno del Guadalete (Arteaga et al., 2008; Llave et al., 1999). Estas posturas defienden la existencia, en la antigüedad, de una amplia ensenada navegable en el estuario del río que ocuparía toda la zona, la cual, a través de la progradación por los aluviones, deforestación, junto a la dinámica oceánica que predomina en la Bahía, propiciaron la progresiva colmatación de este espacioso estuario.

Para el caso del caño de Sancti Petri, desde los documentos más antiguos hasta los más recientes, este brazo de mar ha desempeñado un papel delimitador entre San Fernando y el continente; actuando además como vía de entrada a la Bahía de naves procedentes del Estrecho de Gibraltar, puesto que su navegabilidad queda patente por la presencia del Real Carenero, desde el s. XV, junto al Puente Zuazo, por la construcción del Arsenal de la Carraca a mediados del s. XVIII y por la existencia de cartas náuticas en donde el caño cuenta con sonda batimétrica. Cabe decir que, en las representaciones más antiguas, dominadas por la magnificación de ciertos elementos, este caño presentaba una acusada curvatura (Figura 2) carente del entramado de canales asociados a él. Esta situación dista de la realidad que los mapas del s. XVIII en adelante nos muestran, En ellos el caño se percibe ya con la sinuosidad, los esteros, las salinas y las marismas que lo caracterizan; de esta forma, es evidente la naturaleza de este entorno, fruto de la progradación.

A partir del s. XVII, el número de cursos fluviales representados en la Bahía se incrementa. Ya no se documentan únicamente el Guadalete o el caño de San Pedro, como es nombrado en algunos casos el Caño de Sancti Petri, sino que empiezan a ser representados otros cauces; podríamos decir de carácter

romana impulsada por Lucio Cornelio Balbo, el Menor, en el año 19 a. C.; de esta manera, los autores proponen el estuario del río San Pedro como la desembocadura originaria del Guadalete. 
secundario, como es el Arroyo Salado en Rota, el Caño del Trocadero o el Río Arillo, incrementando el número de unidades hidrográficas representadas.

De los citados, cabe señalar el característico desarrollo del curso del río Arillo; eje que delimita Cádiz con San Fernando, el cual podemos comparar en diferentes documentos cartográficos. En ciertas ocasiones, la cuenca del río aparece semejante a un brazo de mar que conecta las aguas del interior de la Bahía con el mar abierto; en otros documentos, su trazado no llega a alcanzar la costa exterior, permaneciendo parte de su cauce colmatado. Esta situación refleja la morfológica de este espacio, en donde predominan las marismas y salinas; escenario similar en el que se encuentra inserto el caño de Sancti Petri. Atendiendo a los datos paleotopográficos (Alonso et al., 2009: 23) Cádiz y San Fernando -islas que conformaban el antiguo archipiélago gaditano- estarían separadas originariamente. Sin embargo, fruto del proceso de colmatación, la costa de este sector experimentó un proceso de colmatación fusionando las dos islas; de ahí que en muchos documentos se refiera a Cádiz y San Fernando como la ya citada Isla de Cádiz. Este topónimo es síntoma de que estas dos islas se encontraban ya fusionadas desde fechas tempranas, a juzgar por las fuentes medievales.

Junto a la propia dinámica natural de la Bahía, la cual ha condicionado las grandes y pequeñas modificaciones en el paisaje marítimo, la construcción de infraestructuras marítimas y terrestres ha abocado a un paisaje totalmente antropizado. Para ello, únicamente es necesario comparar la Figura 3, e incluso la 6, con la situación actual. La realidad que muestran los primeros planos es de una Bahía prácticamente natural, sin la presencia de grandes construcciones, exceptuando algunas estructuras defensivas dispersas en el paisaje. Los puertos, como el de Cádiz, son naturales carentes de toda estructura portuaria; a excepción de algún espigón o diques, e incluso, por su estratégica localización, estos se encuentran abrigados de forma natural al ser puertos fluviales como el caso del Puerto de
Santa María, mientras que la Bahía se presenta como una amplia ensenada navegable. Todo este paisaje, como ya hemos explicado, cambia notoriamente para finales del s. XIX y XX. Para estos años, la construcción de numerosos puertos aprovechando antiguas ensenadas o estuarios de ríos (Puerto Sherry y el puerto de la Base Naval de Rota), las ampliaciones de los ya existentes, la creación de nuevos Astilleros en Matagorda, la agresiva política de rellenos, unido al éxodo masivo de la población hacia el litoral, han derivado hacia una Bahía profundamente transformada $\mathrm{y}$ totalmente opuesta a ese espacio natural que apreciábamos durante los primeros siglos de la época Moderna.

\section{b) Relieve marino, batimetría y tipos de fondo}

Para recopilar y estudiar este tipo de datos debemos recurrir a las cartas náuticas, por el tipo de información que contienen. Estos documentos contienen datos específicos vinculados a la navegación, como por ejemplo la indicación de las rutas: los puertos, los fondeaderos, el calado, la naturaleza de los fondos y los bajos y escollos peligrosos.

Desde el s. XVI, en donde las primeras cartas náuticas eran escuetas e imprecisas, ya se ponía de manifiesto la presencia de bajos rocosos localizados en plena Bahía exterior. Nos referimos a los bajos del Diamante y la Galera, que obstaculizan la entrada a la Bahía por Cádiz y Rota; así como el resto de bajos que rodean toda la costa septentrional de Cádiz como es el caso de los bajos de las Puercas, el Fraile o los Cochinos. Además de estos bajos, como ya observamos, desde fechas tempranas también se identifican fácilmente accidentes costeros significativos; en este caso, dentro de las puntas más sobresalientes del litoral están las Puntas de San Sebastián, de San Felipe, incluyendo Puntales y Matagorda, las cuales ya resaltamos en el primer bloque temático.

Fruto de las mejoras técnicas, en las que se incluyen el perfeccionamiento en la construcción naval e instrumental para la navegación, surgen cartas náuticas en las 
cuales la información relativa al relieve marino, la batimetría y los fondos, son cada vez más detalladas y precisas llegando a producir auténticas obras de ingeniería militar, como son las obras célebres del Brigadier de la Real Armada Don Vicente Tofiño de San Miguel, o la del Capitán Don José Montojo y Salcedo, en el s. XIX (Figura 5).

Estos documentos más modernos detallan, de forma más explícita, la característica disposición de los bajos peligrosos colindantes a Cádiz; incluso la extensión de las puntas rocosas como son la Punta del Nao, la Punta del Sur o Punta Candor, a los que se unen los arrecifes del León y Placer de los Mártires que discurren paralelos a la costa exterior del istmo hasta llegar a Sancti Petri. Del mismo modo se indican los bajos y lenguas arenosas como Bajo de la Cabezuela, producido por el aporte sedimentario del Río San Pedro, Punta de Clica o la Punta del Boquerón, en plena desembocadura del Caño Sancti Petri, ya que este tipo de fondos son igualmente peligrosos para una nave, pudiendo llegar a desencadenar un desafortunado final. En términos generales, las representaciones de las características de los fondos marinos se hacen más precisas y definidas en los documentos fechados a partir del s. XVIII.

En este sentido, analizando de forma general la morfología de los fondos, se deduce cómo las zonas más rocosas o peligrosas para la navegación de la Bahía se concentran en el contorno de la ciudad de Cádiz; así como en la costa exterior, además del estrecho formado entre Puntales y Matagorda, junto con la costa de Rota y los aledaños al islote de Sancti Petri y la desembocadura del caño homónimo. 


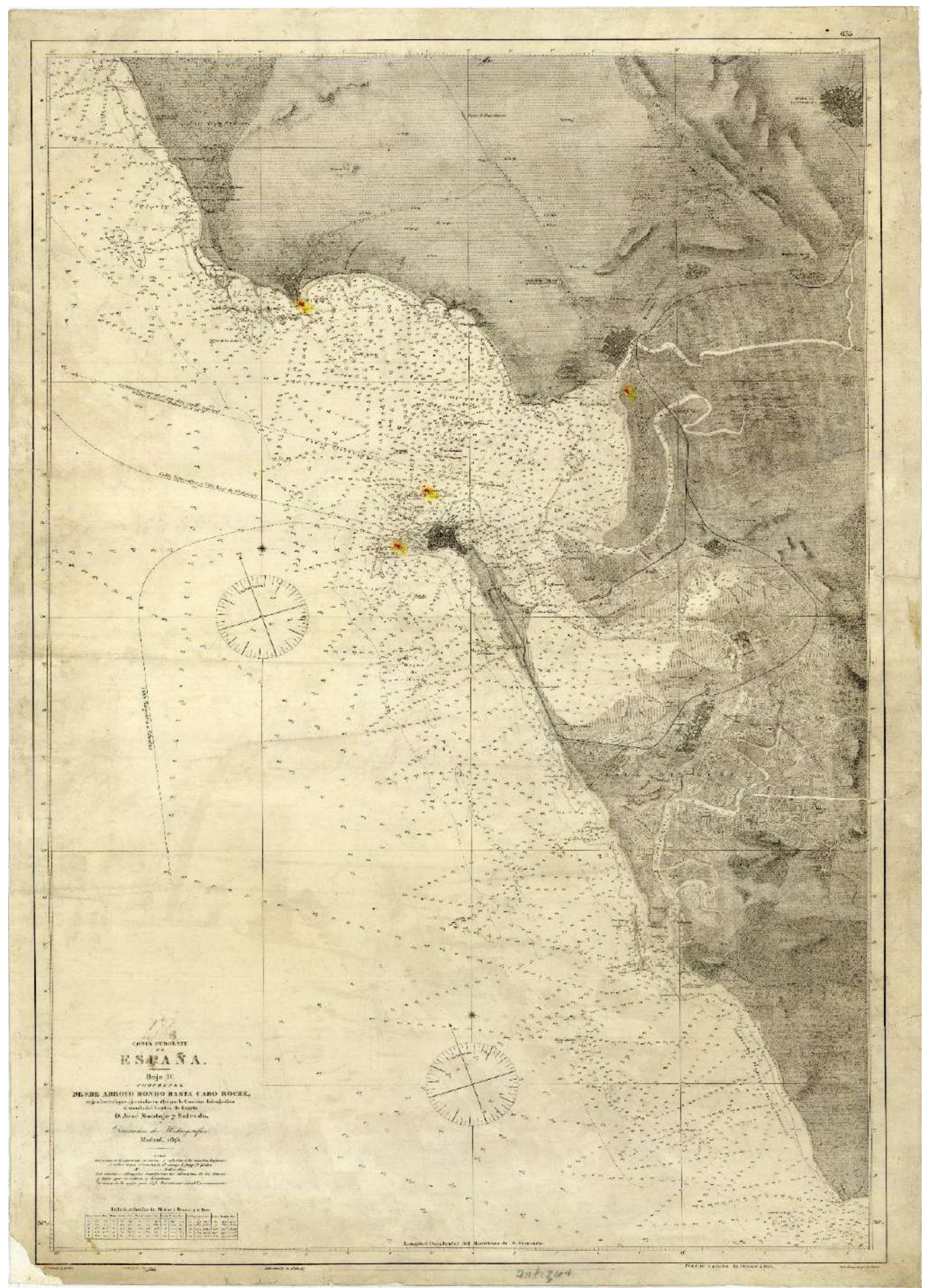

Figura 5: Carta de José Montojo y Salcedo de 1875 (Instituto Geográfico Nacional. S1-35-N34)

Jangwa Pana: Revista de Ciencias Sociales y Humanidades -Vol. 18, No. 2, enero-abril de 2019 DOI: https://doi.org/10.21676/16574923.2926 
Gracias a las cartas náuticas podemos identificar también las zonas de la Bahía más profundas, a través de la información que nos aporta la batimetría. Este tipo de datos se incorporan de forma más generalizada en documentos fechados a partir del s. XVIII, pues previamente los datos batimétricos resultaban muy efímeros. Si atendemos a las cartas, en general, las áreas más profundas se registran en la canal principal de acceso hasta casi alcanzar Puerto Real, en la Bahía exterior y en la franja litoral orientada hacia mar abierto entre Cádiz y la Punta del Boquerón (Figura 6).
En contraposición, las áreas con menos profundidad se registran, sobre todo, en la Bahía interior con valores inferiores a un metro; también en la ensenada de la playa de la Caleta y el puerto de Cádiz, junto a zonas cercanas a la costa de la Bahía de los Toros. Sin embargo, para algunas zonas podemos comprobar, gracias a los documentos más recientes, la variación del calado en determinadas zonas, adquiriendo mayor profundidad; como es el caso del puerto de Cádiz, fruto de la obra de los dragados ${ }^{20}$.

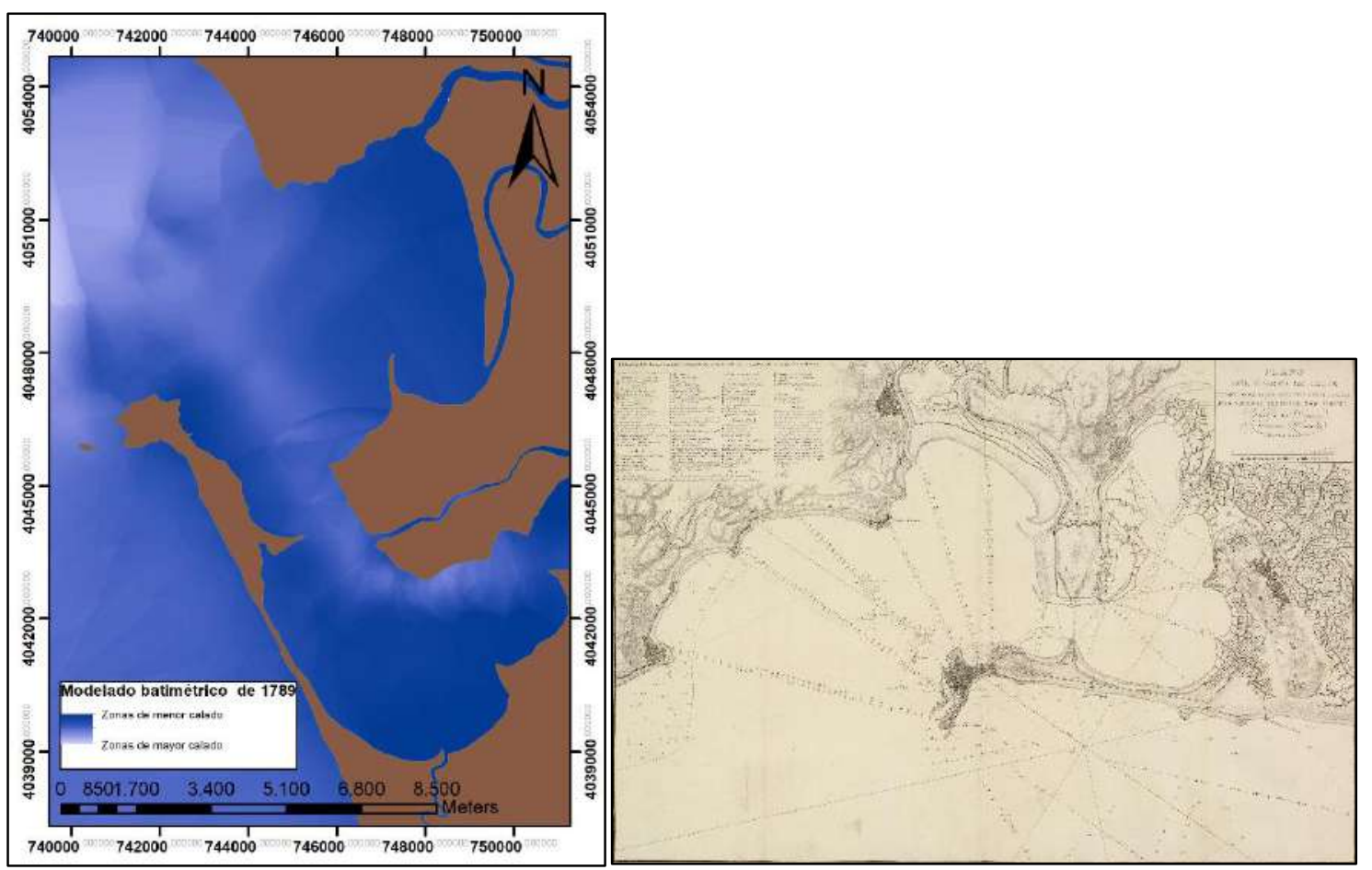

Figura 6: Modelado batimétrico de la Bahía a finales del s. XVIII (Izquierda), con base en los datos batimétricos de la carta náutica de Don Vicente Tofiño (Derecha) (Institut Cartogràfic i Geològic de Catalunya. RM. 23986). Mapa elaborado con ArcMap versión 10.5

Otro dato, que también nos aportan las cartas náuticas, es la tipología de los fondos; información que aparece, en ocasiones, junto a la propia batimetría. Para la Bahía de época Moderna y Contemporánea, el tipo de fondo que prolifera se caracteriza por las arenas mezcladas con lodo y fango, las cuales se intercalan con fondos rocosos. Las arenas tienden a concentrarse en el saco interior convirtiéndola en una ensenada cada vez más colmatada; mientras que, en la bahía exterior, además de arenas, nos encontramos con fondos pedregosos que abundan, lógicamente, en las proximidades a los bajos rocosos de la Galera, el Diamante, las Puercas, el Fraile y todos los escollos que se detectan en las proximidades de la costa de Cádiz. También se registran fondos rocosos en la costa de Rota, junto con los arrecifes y placeres que se disponen frente a la costa occidental del istmo, concentrándose en

\footnotetext{
${ }^{20}$ Factor que también debemos tener en cuenta a la hora de analizar la progresión del calado en una determinada zona.
} 
la zona de Torregorda. En el área cercana al islote y desembocadura del caño de Sancti Petri, también se registran fondos arenosos localizados en mayor medida en la bocana del caño; mientras que en los aledaños al islote abundan las rocas (Figura 4).

\section{c) Mecanismos para la movilidad: orografía, elementos de señalización, rutas de navegación y enfilaciones}

Gracias a la cartografía histórica podemos identificar también ciertos elementos que facilitarían el acceso, la salida y la circulación dentro de la Bahía; elementos que han sido, en cierto modo, integrados en la cultura del navegante, formando parte de ese mapa mental, mediante el cual le permite ubicarse y mantener la ruta. Nos referimos a las distintas demarcaciones costeras de diversa naturaleza, como las torres vigías y faros, además de unidades del relieve destacables.

Desde el siglo XVI, el hito geográfico más representado y significativo, en comparación con otras unidades de la orografía gaditana, ha sido la colina sobre la que se asienta Medina sidonia, el Cerro del Castillo; cuenta con una altitud de más de 400 metros sobre el nivel del mar, situado a unos $45 \mathrm{~km}$ de la Bahía. Como sabemos, las costas bajas constituyen el paisaje predominante en la Bahía; de este modo, atendiendo a la altitud de este cerro y a su constante aparición, podría considerarse como punto de referencia para la navegación.

Junto a Medina Sidonia se registran, a partir del s. XVII, un considerable número de cerros y sierras que despuntan en el paisaje, como, por ejemplo: la Sierra e Gibalbín en Jerez de la Frontera; la Sierra de San Cristóbal y Cerro de Santa Isabel en el Puerto de Santa María; el Cerro de Carretones; el Cerro de Ceuta en Puerto Real; el Cerro de Torre Alta; y Cerro de los Mártires en San Fernando; así como el Cerro de Santa Ana en Chiclana de la Frontera. No obstante, a partir del s. XIX, también se presta especial atención al relieve del cinturón litoral de la Bahía de los toros, en donde destacan suaves elevaciones, conformadas por dunas en su mayoría.

Además del uso de estos hitos naturales para apoyar la navegación en la Bahía, documentamos faros y torres, dispositivos que constituyen otro tipo más de referentes para la navegación. Desde el s. XVI, las estructuras que identificamos son las famosas Torres de Hércules localizadas en la actual playa de Torregorda; además de unas torres de guardia localizadas en la zona del Campo de Sur. Ya para el s. XVII, el número de construcciones se incrementa; se documentan, además de las anteriormente citadas, Torre Bermeja, Torre de Sancti Petri, Torrealta, Torre de San Sebastián, Torre del Fuerte de Santa Catalina del Puerto o la Torre de los Cañuelos en la Bahía de los Toros. Para el s. XVIII algunas de estas torres fueron transformadas en faros, como el caso del faro de San Sebastián, mencionado en la cartografía como la Linterna de San Sebastián; las Torres de Hércules pasaron a ser una única construcción llamada Torregorda, y aparece en el punto más alto de la capital: aparece una torre vigía llamada Torre Tavira. En el s. XIX se suma, a este sistema de señalización, el faro de Rota, y una serie de balizas localizadas en diversos bajos peligrosos junto al faro de Sancti Petri a comienzos del s. XX.

Como podemos ver, los faros que se inscriben en el ámbito de la Bahía fueron el resultado de la remodelación de antiguas torres de vigilancia ubicada en zonas estratégicas (Falcón, 1989), las cuales formaban parte de un sistema defensivo más extenso. Según apuntan algunos estudios, esta red de torres de vigilancia que jalonan la costa ${ }^{21}$ atiende a un sistema de señalización, heredado desde época medieval como método por el cual podían divisar la llegada de barcos enemigos o mercantes, a la vez de actuar como elementos de señalización marítima.

La disposición de estos dispositivos, y su continuidad a lo largo del tiempo, llama

\footnotetext{
21 Torre Bermeja, Torre de Sancti Petri, Torres de Hércules (Torregorda) y Torre de San Sebastián.
} 
forzosamente la atención, pues lleva a preguntarnos por las características físicas del enclave en sí; del porqué era necesario un elemento distintivo, y de su posible relación con antiguas estructuras ${ }^{22}$. En algunos casos, la localización de estos, permite establecer líneas de enfilación que a su vez señalan la derrota que una nave debe seguir para acceder o partir de la Bahía.

El principal acceso, según se indican en las cartas antiguas, se basó en la misma entrada por la que hoy acceden los buques, navegando entre Cádiz y Rota. Esta ruta viene marcada en los documentos desde los s. XVI y XVII; sin embargo, a partir del s. XVIII, las rutas parecen aumentar, produciéndose una bifurcación de la entrada tradicional. Para ello, un navegante podía tomar la derrota marcada por el Canal de los Holandeses ${ }^{23}$; por la Canal Principal ${ }^{24}$, o por el Canal del $\mathrm{Sur}^{25}$, sorteando los diversos obstáculos.

Para las naves de menor calado y de fácil maniobrabilidad, procedentes del Estrecho de Gibraltar, podrían acceder a la Bahía de forma más rápida tomando el caño de Sancti Petri como atajo. De igual modo, para acceder al Caño, el marino podía optar por el Canal del Boquerón ${ }^{26}$ o por el Canal Sudeste ${ }^{27}$.

La orografía, los accidentes costeros, las torres y los faros, irán marcando las diferentes rutas de acceso por medio de enfilaciones. De este modo, y a raíz de los datos que podemos extraer de las cartas náuticas partir del s. XVII, estas enfilaciones eran tomadas sobre puntos conspicuos del paisaje costero. La primera

\footnotetext{
${ }^{22}$ Un claro ejemplo de ello es el caso de Torregorda, en donde actualmente se ubica una torre de señalización. En dicho enclave, se ubicaron dos torres almadraberas, en época moderna conocidas como Torres de Hércules, junto a un corral de pesca, a la luz de los datos que nos aporta la propia cartografía y grabados de la época. Además, la historiografía ha localizado en este mismo punto el antiguo faro romano de Gades, a la luz de los testimonios árabes (Ordóñez, 1990, Fear, 1993; Gómez, 2016, en prensa). De ser certera dicha teoría, podemos observar un claro vínculo con lo marítimo desde la Antigüedad hasta nuestros días, albergando, dicho lugar, distintas estructuras que podrían facilitar la navegación por la zona.

${ }^{23}$ Navegando entre la costa y el Bajo de la Galera.
}

línea de enfilación que nos encontramos, y que es utilizada hasta el s. XX, es la formada entre Medina Sidonia y la torre campanario de la Iglesia de San José en Puerto Real; dicha línea marcaba la entrada a la Bahía por el Canal Principal, es decir, entre el bajo del Diamante y las Puercas. Para acceder entre los bajos del Diamante y la Galera, se utilizaba como puntos de enfilación el Fuerte de Matagorda y el Real Observatorio de la Armada, localizado en Torrealta; mientras que para llegar a la Bahía interior, a través del Canal de los Holandeses, se debía tomar la enfilación marcada por Torregorda y el Castillo de Puntales ${ }^{28}$.

\section{d) Funcionalidad del espacio marítimo: desarrollo de actividades económicas en la costa, explotación de recursos marinos y puertos}

Por todos es sobradamente conocida la tradición y dedicación marítima de la que es característica la Bahía desde época fenicia. Esta no solo ha estado vinculada a la navegación y comercio que tenía lugar en su celebérrimo puerto, sino también a la explotación de los recursos naturales que el mar ofrece y con los que se comerciaba; de ahí que hayamos dedicado una parte del estudio a analizar cómo se articulaban los espacios destinados a diversas actividades económicas. Dichas actividades, también documentadas en la cartografía, se ciñen a la explotación de salinas, corrales de pesca, actividad almadrabera y astilleros para construcción y reparación de naves.

\footnotetext{
${ }^{24}$ Entre el Bajo de la Galera y el Diamante, o también entre el Diamante y las Puercas.

${ }^{25}$ Navegar entre el Bajo de la Fridera y Punta del Nao. Acceso documentado por la cartografía a partir del s. $\mathrm{XX}$.

26 Canal conformado entre la punta homónima y el arrecife donde se localiza el islote de Sancti Petri, acceso ideal para las naves procedentes del norte.

${ }^{27}$ Acceso entre la Punta del Bajo del Poniente y Punta de las Piedras.

${ }^{28}$ Además de las enfilaciones descritas, la famosa carta náutica, ya citada, creada por el Brigadier de la Real Armada Don Vicente Tofiño de San Miguel, ofrece muchas más, las cuales se apoyan en estructuras moderno- contemporáneas.
} 
La actividad salinera es la que mejor aparece documentada. Normalmente se localizan en sendos márgenes del caño de Sancti Petri, en el entorno del río Arillo y en el área comprendida entre el cauce del Guadalete y río San Pedro; e incluso en el área de Matagorda y la isla del Trocadero. Por tanto, favorecido por el tipo de paisaje natural que predomina en la Bahía, las salinas siempre han caracterizado el paisaje de nuestra Bahía. No obstante, tras el auge de este tipo de explotación, se produce una recesión considerable de la actividad durante ese proceso de profunda transformación que sufre la Bahía durante el pasado siglo, llevando a cabo muchísimas desecaciones de las mismas para la disposición de suelos industriales.

Desde época prehistórica, los distintos pueblos que se han asentado en la Bahía han sido comunidades necesariamente enfocadas $y$ proyectadas al mar; centradas en el aprovechamiento de los recursos para el consumo propio y comerciar con ellos, por lo que la pesca era una actividad cotidiana. Tal y como se observa en mapas, planos, y también ${ }^{29}$ en los grabados, las actividades haliéuticas podían desarrollarse de forma tradicional con caña y cebo, o bien mediante un sistema de corrales de pesca o almadraba en zonas donde el tránsito de las diversas especies es más propicio.

El corral de pesca más antiguo que documentamos es el corral ubicado en los aledaños de la Ermita de San Sebastián en el s. XVII ${ }^{30}$; además de los corrales documentados en la actual playa de Santa María del $\operatorname{Mar}^{31}$ y en la Punta de las Vacas ${ }^{32}$. Estos corrales, aparentemente, estuvieron en uso al menos hasta el s. XVIII; a partir de esta fecha adquiere cierta relevancia el famoso corral de Vives,

\footnotetext{
${ }^{29}$ A pesar de no corresponder a un tipo de documento cartográfico, las vistas realizadas en esta época constituyen una fuente de documentación muy valiosa para estudiar, a partir de la iconografía de la época, diversos aspectos no sólo del paisaje, sino también de la vida cotidiana.

30 Aparentemente un corral cuya estructura está escavada en la roca natural y que hoy en día puede apreciarse durante la bajamar.

${ }^{31}$ Hoy en día también conocida como la playa de Los Corrales.
}

situado en la zona actual de la playa de Torregorda, el cual se mantuvo en funcionamiento hasta el s. XX; podríamos decir que fue el corral que estuvo en uso durante más tiempo. Ya para finales del s. XIX y comienzos del XX, junto al corral de Vives, estuvieron en activo otros corrales de pesca localizados en la franja costera de la Bahía de los Toros, además de los corrales ubicados entorno a Punta Candor y el documentado en las inmediaciones del Castillo de Santa Catalina.

En lo referente a las almadrabas, estas se localizan en zonas puntuales y de tradición pesquera como es el caso de la Punta de las Vacas, la almadraba de Hércules - también llamada almadraba de Torregorda, la cual estuvo activa durante los siglos XVI y XVIIy la almadraba de Punta Candor ya para fechas más recientes.

Analizando la disposición de estas estructuras y los espacios dedicados a la pesca en el entorno marítimo de la Bahía, podemos identificar determinadas áreas que, ya sea por sus características naturales, son idóneas para desarrollar este tipo de actividades; a juzgar por el prolongado uso en el tiempo de estas zonas destinadas a desarrollar una misma actividad. Este fenómeno de continuidad se constata, como ya vimos, en la zona actual de Torregorda, cuyas antiguas torres se han identificado como antiguos avistaderos de atunes (Bernal, 2008, p.93). Este mismo fenómeno se repite para la zona de la Caleta, en donde se percibe una larga tradición pesquera $^{33}$, la cual se materializa en los corrales de San Sebastián y Santa Catalina; así como en la Punta de las Vacas o en Punta

\footnotetext{
${ }^{32}$ Localizada en los bajos rocosos llamados también Los Corrales

33 Tradición vinculada a la explotación de los recursos marinos desde época romana, pues, fruto de las obras para nuevas construcciones, se documentó una factoría de salazones en el actual Club Náutico de la Caleta en la década de los años 80 del pasado siglo. Esta apareció muy alterada debido a las obras de construcciones defensivas del s. XVII (Lagóstena, 2001:112).
} 
Candor en Rota, en donde también se registran corrales y almadrabas.

El establecimiento de puertos también supone un elemento mediante el cual se articulan los espacios marítimos con base en su funcionalidad, pues en los puertos era donde tenían lugar las transacciones económicas, entre otras actividades. Tal y como podemos comprobar, el puerto más representativo que actúa como epicentro del flujo comercial en la Bahía desde hace siglos, ha sido, y es, el puerto de Cádiz; el cual ha estado representado de forma ininterrumpida en toda la compilación cartográfica que disponemos. La morfología que presenta este puerto resulta de lo más característico, pues desde las primeras representaciones se muestra como un puerto natural hasta casi llegados al s. XIX, fecha en la tienen lugar las grandes infraestructuras portuarias. Este puerto, que originariamente estaba conformado por una playa, se encontraba refugiado de los vientos y corrientes por el muelle de San Felipe, en donde el escaso calado cerca de la costa se evidencia gracias a las vistas de la época. En ellas se puede apreciar un puerto de mareas en el que solo pueden acceder pequeñas embarcaciones, las cuales transportaban mercancías y pasajeros desde las grandes naves fondeadas en mitad de la Bahía hasta tierra firme. Con el paso de los años este puerto experimenta profundos cambios, tras la construcción de diversos diques, ampliando así su extensión, dejando atrás ese puerto natural.

Así mismo, entorno al puerto gaditano, existen otros puertos menores localizados en entorno de la Bahía como son: el puerto de Rota, el puerto de Puerto Real o el puerto fluvial del Puerto de Santa María ${ }^{34}$, proyectado en la ribera septentrional del río. Este puerto constituyó un punto de recalada previo al remonte del río, y zona por la cual transcurren y parten naves con mercancías procedentes del interior.

\section{e) Elementos del paisaje cognitivo: toponimia}

Gracias a la toponimia que encontramos inserta en la cartografía histórica podemos conocer ciertas características paleotopográficas de determinadas áreas, que hoy se encuentran totalmente alteradas o camufladas; incluso, nos puede indicar antiguos usos de una zona específica o asociados a una estructura concreta, y así documentar su continuidad a lo largo del tiempo. De este modo, el estudio de la ubicación del topónimo, y su entorno en general, es fundamental para el análisis del paisaje marítimo antiguo; en otras palabras, la toponimia puede ayudarnos a recrear cómo era la percepción del paisaje marino y su apropiación por parte de las comunidades marítimas.

La cantidad de topónimos introducidos en la cartografía de la Bahía fue multiplicándose de forma gradual, ya que los mapas del s. XVI no tienden a contener apenas información escrita, situación que contrasta con los documentos a partir del s. XVII y XVIII.

La toponimia de carácter marítimo, contenida en los documentos cartográficos, la hemos organizado en diferentes grupos con base en su significado, estableciendo un total de seis $^{35}$; siendo estos:

- Topónimos que indican zonas peligrosas para la navegación. Ejemplos: Rompetimones, Punta del Nao o Bajo de la Olla.

- Topónimos que aluden a características paleotopográficos o geomorfológicos. Ejemplos: la Barra, el Boquete, Albufera, la Caleta de Rota, Het Eiland (La isla), Río Salado o Puerto Chico.

- Topónimos que apuntan posibles restos arqueológicos. Ejemplo: Pozo del Romano.

\footnotetext{
${ }^{35}$ Algunos topónimos, por su significado, pueden estar

asociados a más de un grupo.
}

\footnotetext{
34 Puerto de relevancia aparentemente desde la antigüedad dada su identificación con el famoso puerto romano de Gades (López y Pérez, 2013, p. 107).
} 
- Topónimos que citan elementos de señalización costera. Ejemplo: Torregorda, Bajo del Vigía, Linterna de San Sebastián, Torres de Hércules.

- Topónimos que indican antiguas rutas de navegación. Ejemplo: el Canal de los Holandeses.

- Topónimos relacionados con antiguos usos del espacio. Ejemplo: Puerto Chico o Batería de la Primera y Segunda Aguada.

\section{f) Registro arqueológico}

La información sobre el registro arqueológico que documentamos en la zona de estudio a partir de la arqueología resulta bastante escueta; exceptuando algunas referencias, debido a la profunda antropización y constante ocupación hasta nuestros días. En primer lugar, podemos documentar evidencias antiguas en el paisaje moderno a partir de la propia toponimia; nos referimos concretamente al topónimo "Pozo o Batería del Romano", cuya localización casa a la perfección con la ubicación de la antigua necrópolis de la ciudad antigua a Extramuros. De este modo, posiblemente el topónimo alude a la existencia de alguna antigua estructura ${ }^{36}$.

Por otra parte, en la cartografía también documentamos restos de antiguas fortificaciones, o trazados de la muralla defensiva, que hoy en día no se han conservado o simplemente presentan un estado de deterioro considerable; como es el caso del fuerte de San Luis en la Isla del Trocadero, el castillo de Santa Catalina en el Puerto de Santa María y el resto de fortines que durante el s. XVIII y XIX se erigían en plena costa portuense y roteña. Estas, eran estructuras que en su tiempo formaron parte del sistema defensivo de la misma Bahía, sobre todo en los períodos bélicos.

\section{Conclusiones}

Gracias a este trabajo hemos podido poner de manifiesto, en primer lugar, la validez y funcionalidad del método expuesto para estudiar, de forma organizada, el paisaje marítimo de un área concreta; dada la riqueza de información contenida en los mapas, cartas y planos de la Bahía. En este sentido, destacamos, una vez más, la trascendencia de la cartografía histórica como una fuente fundamental para analizar el paisaje cultural marítimo.

A la luz de los resultados tras el análisis cartográfico, parece que este tipo de documentos resultan muy útiles para analizar los cambios geomorfológicos que la costa ha ido experimentando en el devenir de los siglos. En nuestro caso, documentamos una profunda transformación desde las primeras representaciones de la Bahía en donde se presentaba como una proclive a ofrecer abrigo al navegante, dada la morfología y orientación de la costa. Mientras que, desde el s. XIX, esta experimenta un profundo cambio en cuanto a su aspecto, debido a la propia dinámica natural y la intervención antrópica en el medio; perdiendo, de esta forma, gran parte de su carácter natural que antaño la caracterizaba. Como hemos podido ver, una de las zonas más alteradas ha sido toda la costa oriental de Cádiz y su istmo, así como Matagorda o la desembocadura del Guadalete; zonas las cuales hemos podido analizar, en clave diacrónica, su evolución, hasta alcanzar su situación actual.

Desde una perspectiva náutica, y a pesar de que la Bahía, para la época moderna, contaba con todo un sistema de señalización bastante desarrollado; la navegación por la misma no debió de ser fácil. En primer lugar, por el predominio de costas bajas que la caracteriza; por ello la constante representación de las diferentes alturas próximas a la costa, gracias a las cuales establecían líneas de enfilación, como es el caso de Medina. Y en segundo, por

documentado en un grabado de la capital gaditana del s. XVI, asociado por múltiples investigadores al antiguo anfiteatro romano, el cual hoy no se conserva. 
la presencia de bajos y escollos rocosos que obstaculizan y a la vez dificultan el acceso y salida por la bocana principal; como son los famosos bajos de las Puercas, la Galera y el Diamante. Es por ello que, para estudiar este tipo de aspectos, las cartas náuticas resultan imprescindibles.

Este método, a pesar de poner de manifiesto la utilidad de la cartografía y el volumen de información, susceptible de ser analizada, que parte de la misma, su funcionalidad difiere en función, lógicamente, de la zona a la que es aplicado y al marco cronológico al que nos ceñimos. Resulta más que evidente que los datos que la cartografía nos aporta, de todos los factores estudiados, permiten al investigador, el cual estudia el paisaje costero moderno, acercarse a la realidad con mayor rigor que en el caso de estudiar el paisaje de época antigua o medieval. Podríamos decir que su valor, para estos estudios, deriva del carácter coetáneo de la propia fuente.

Por último, queremos resaltar la relevancia de la interdisciplinariedad. A pesar de lo fructuoso que puede llegar a constituir un análisis cartográfico es importante, para llevar a cabo un estudio íntegro, la incorporación de datos aportados a partir de las fuentes literarias, arqueológicas o geoarqueológicas; lo que nos ayudará a una mejor y mayor comprensión de ese paisaje marítimo, a lo largo de los siglos, y de las diferentes culturas que lo han habitado.

\section{Agradecimientos}

Amerita especial agradecimiento a mi compañero Francisco Ghersi, por el material facilitado y por introducirme en el mundo de la cartografía histórica, y a los profesores Doña Alicia Arévalo y Don Alberto Gullón, por llevarme por buenos derroteros durante este trabajo.

\section{Referencias Bibliográficas}

Abellán, J. (2005). El Cádiz islámico. A través de sus textos. Cádiz, España: Servicios de publicaciones de la Universidad de Cádiz.
Alonso Villalobos, C., Gracia Prieto, F.J., Ménanteau, L. (2003). Las salinas de la Bahía de Cádiz durante la Antigüedad: visión geoarqueológica de un problema histórico. Revista Spal, 12, 317-332.

Arteaga, O., Kölling, A., Kölling, M., Roos, A. M., Schulz, H., Schulz, H. D. (2002). El Puerto de Gadir. Investigación geoarqueológica en el casco antiguo de Cádiz. Revista Atlántica-Mediterránea de Prehistoria y Arqueología Social (RAMPAS), 4, 345-415.

Arteaga, O., Schulz, H.D., Roos, A. M. (2008). Geoarqueología dialéctica en la Bahía de Cádiz. Revista AtlánticaMediterránea de Prehistoria y Arqueología Social (RAMPAS), 10, 21116.

Bernal, D. (2008). Gades y su bahía en la Antigüedad. Reflexiones geoarqueológicas y asignaturas pendientes. Revista AtlánticaMediterránea de Prehistoria y Arqueología Social (RAMPAS), 10, 267-308.

Bustos, M. (2008). La topografía urbana del Cádiz moderno y su evolución. Revista Atlántica-Mediterránea de Prehistoria y Arqueología Social (RAMPAS), 10. 413- 444.

Cerezo, F. (2016). Los puertos antiguos de Cartagena. Geoarqueología, arqueología portuaria, paisaje marítimo. Un estudio desde la Arqueología náutica. Tesis doctoral. Universidad de Murcia.

Chevallier, R. (2000). Lecture du temps dans l'espace. Topographie archéologique et histoire. Paris, Francia.

Cobos, D. (1993). La Bahía de Cádiz. Aproximaciones a un diagnóstico cartográfico de la evolución del paisaje. Cuadernos de Geografía, 4, 137-154. 
Cortés, J. (1998). La Cartografía Histórica. Boletín de la A.G.E (Asociación de Geógrafos Españoles) $n^{o}$ 16, 41-54.

Duncan B., Gibbs M. (2015). Shipping mishaps and the Maritime Cultural Landscape. En Duncan B., Gibbs M. (Eds): Please god send me a wreck. When the land meets the sea (An ACUA and SHA Series), vol. 3 (pp. 723). New York, United States: Springer.

Falcón, T. (1989). Los Faros de la costa atlántica andaluza. Consejería de Obras Públicas y Transportes. Centro Estudios Territoriales y urbanos. Sevilla, España.

Fear, T. (1993). The tower of Cadiz. Faventia, 12-13.

Gómez Muñoz, Ma . S. (2016). Estudio de visibilidad mediante SIG del faro romano de Gades. I Jornadas de Jóvenes Investigadores en Arqueología. (En prensa).

Jiménez Vialás, H. (2008). An approach to landscape changes in the bay of Gibraltar through the cartografy. En Cristina Corsi y Frank Vermeulen (Eds.): Changing landscapes. The impact of Roman towns in the western Mediterranean. Proceeding of the International Colloquium, 237-258.

Lagóstena, L. (2001). La producción de salsas y conservas de pescado en la Hispania Romana (II $a$. C - VI d. C). Barcelona, España: Universidad de Barcelona.
Llave, E., Hernández-Molina, F.J., Alonso, C., Gallardo, M., Vázquez, J.T., LópezAguayo, F. (1999). Caracterización y evolución del paleopaisaje del río Guadalete en la Bahía de Cádiz durante el cuaternario terminal. Geogaceta, 26, 43-46.

López Amador, J. y Pérez Fernández, E. (2013). El Puerto Gaditano de Balbo. Cádiz, España.

Ordóñez, S. (1993). El faro de Gades y las fuentes medievales. II Congreso Peninsular de Historia Antigua. Coimbra. Portugal.

Porro Gutiérrez, J. (2011). La Cartografía histórica como fuente para la investigación histórica y patrimonial (Antiguiedad y E. Media). Revista $P H$, IAPH. N $N^{a} 77$ Monográfico, 54-61.

Sáez Romero, A. M. y Díaz Rodríguez, J. J. (2012). Entre tierra y mar, entre lo púnico y lo romano. Adaptaciones económicas y territoriales en un medio cambiante: algunas notas sobre paleogeografía y sistemas de explotación del hinterland insular de Gadir/Gades. En Mora Serrano, B. y Cruz Andreotti, G.: La etapa neopúnica de Hispania y el Mediterráneo centro occidental: identidades compartidas (pp. 259- 300). Sevilla, España: Universidad de Sevilla.

Westerdahl, C. (1992). The maritime cultural landscape. The International Journal of Nautical Archaeology 21.1. 5-14. 